\title{
The preoperative serum ratio of total prostate specific antigen (PSA) to free testosterone (FT), PSA/FT index ratio, and prostate cancer. Results in 220 patients undergoing radical prostatectomy
}

\author{
Antonio B. Porcaro ${ }^{1}$, Beatrice Caruso ${ }^{2}$, Alessandro Terrin ${ }^{1}$, Nicolò De Luyk ${ }^{1}$, \\ Giovanni Cacciamani ${ }^{1}$, Paolo Corsi ${ }^{1}$, Davide Inverardi ${ }^{1}$, Davide De Marchi ${ }^{1}$, \\ Roberto Baldassarre ${ }^{1}$, Mariangela Cerruto ${ }^{1}$, Claudio Ghimenton ${ }^{3}$, Matteo Brunelli ${ }^{3}$, \\ Stefano Zecchini Antoniolli ${ }^{1}$, Aldo Petrozziello ${ }^{4}$, Walter Artibani ${ }^{1}$ \\ ${ }^{1}$ Urologic Clinic, ${ }^{2}$ Department of Laboratory Medicine, ${ }^{3}$ Department of Pathology, ${ }^{4}$ Department of Geriatric Medicine \\ University Hospital, Ospedale Policlinico, Azienda Ospedaliera Universitaria Integrata, Verona, Italy.
}

\begin{abstract}
Summary Objectives: To evaluate associations of preoperative total prostate specific antigen (PSA) to free testosterone (FT), the PSA/FT index ratio, with features of pathology prostate cancer (PCA) and to investigate its prognostic potential in clustering the PCA population. Patients and methods: After excluding criteria, the records of 220 patients who underwent radical prostatectomy (RP) were retrospectively reviewed. Serum samples of PSA, total testosterone (TT) and FT were collected at 8.00 A.M., one month after biopsies and before RP. The PSA/FT ratio was computed in the population of patients who were clustered in groups according to ranking intervals of the PSA/FT ratio which identified at least 4 clusters which were coded as A, B, C, and $D$. The independent associations of the PSA/FT index ratio were assessed by statistical methods and a two-sided P $<0.05$ was considered to indicate statistical significance.

Results: TT correlated to FT which was a significant predictor of PSA in the population of patients who were subsequently clustered, according to increasing interval values of the PSA/FT index ratio, in groups that showed a stronger linear association of FT with PSA. The PSA/FT index ratio significantly associated with pathology features of prostate cancer such as pathology Gleason score ( $p G S)$, invasion of the seminal vesicles $(p T 3 b)$, proportion of positive cores $(P+)$ and proportion of cancer involving the volume of the prostate. In the population of patients, TT, PSA/FT index ratio and P+ independently associated with $p G S \geq 7$ and $p T 3 b$; moreover, the odds ratio (OR) of the PSA/FT index ratio resulted 9.11 which was stronger than $T T(O R=1.11)$ and $P+(O R=8.84)$. In the PCA population, TT, PSA/FT index ratio and $P+$ also independently associated with $\mathrm{pT} 3 \mathrm{~b}$ PCA; interestingly, the OR of PSA/FT index resulted 54.91 which was stronger than $T T(O R=1.31)$ and $P+(26.43)$.

Conclusions: Preoperative PSA/FT index ratio is an independent strong factor which directly associates with aggressive features of pathology PCA; moreover, it might express prognostic potential for clustering the patient population in risk classes. Confirmatory studies are required.
\end{abstract}

KEY WORDS: Prostate cancer; Prostate specific antigen; Total testosterone; Free testosterone; Pathology Gleason score; Seminal vesicle invasion.

Submitted 3 March 2015; Accepted 14 July 2015

\section{INTRODUCTION}

The biology of the prostate gland is closely related to the endocrine system which includes the hypothalamus, the pituitary, the adrenals and the testes. The interstitial cells of Leydig of the testes are responsible for the production of $95 \%$ of all circulating androgens in the form of total testosterone (TT). Approximately $98 \%$ of the circulating androgens are bound to plasma proteins, including a specific beta-globulin, testosterone-binding globulin (TeBG). The free testosterone (FT) in the blood is the physiologically important fraction.

It has been shown that prostate cancer (PCA) is an endocrine tumor which is androgen dependent (1) and associates with increased PSA serum levels $(2,3)$. Since the pioneering work of Charles Huggins (1), androgens have been universally considered as being pivotal in the regulation of normal function and malignant growth of the prostate; moreover, pretreatment TT serum levels have been detected abnormal in the PCA population (4-7).

Actually, according to updated statistics, PCA, in the USA as in Europe, is, after lung cancer, the second most frequent solid tumor in adult males (8). Moreover, it has been estimated a cumulative risk of $3.9 \%$ and a mortality rate of $1.2 \%$ for PCA (9). The stratification of PCA patients in clinical class risk (CCR) groups is important for planning treatments of low (L), intermediate (I) and high (H) PCA CCR (10). The inclusion of PCA patients in CCR classes involves the computation of total prostate specific antigen (PSA), biopsy Gleason score (bGS) and clinical staging $(\mathrm{cT})$. However, although being an endocrine dependent tumor, PCA is generally staged without investigating on hormonal features. As a result, the CCR of PCA patients do not include endocrine features which may relate to tumour biology.

The primary aim of the study was to evaluate independent associations of preoperative total PSA to FT ratio, the PSA/FT index ratio, with features of pathology PCA. The secondary endpoint of the trial was to investigate the prognostic potential of the PSA/FT index ratio for clustering the PCA population into risk classes. 


\section{Patients And methods}

The present study, carried out from 2007 to 2011, was part of a larger trial which aimed at evaluating a potential link between PCA and the hypothalamus - pituitary - testis - prostate axis. The investigation included only patients who had not previously received $5 \alpha$-reductase inhibitors, LH-releasing hormone analogues or testosterone replacement treatment. The trial was retrospective and included patients who underwent standard retropubic prostatectomy (RRP) which was eventually associated with local lymph node dissection (LND). The diagnosis of PCA was performed by the 14-core Trans Rectal Ultrasound Scan (TRUS) guided prostate biopsy technique which also included additional cores of lesions detected by either TRUS and/or digital rectal examination (DRE). The biopsy Gleason score (bGS) of positive cores was assessed by an experienced pathologist. The percentage of positive cores $(\mathrm{P}+)$ detected by TRUS was computed after diagnosis of PCA. The prostatectomy specimens were fixed in toto overnight (10\% neutral buffered formhaldeyde), coated with India ink and then weighted (Wi). Tissue sections of $4 \mu \mathrm{m}$ were prepared in standard fashion and stained with hematoxylin and eosin. Patients were classified according to primary tumor stage, lymph node and metastatic status, using the TNM categories. Patients were then classified according to the D'Amico CCR groups (10). Tumors invading and extending beyond the capsule were coded as pT3a. Invasion of the bladder neck without involvement of the seminal vesicles was also staged as pT3a. Seminal vesicle invasion was defined as tumor involving of the muscular wall and was coded as pT3b. Surgical margins $(\mathrm{SM})$ were stated as free $(\mathrm{N})$ or involved by cancer (P). Tumors were graded according to the Gleason grading system and the pathology Gleason score (pGS) was computed after summing up the two pathology Gleason patterns (pGP), prevalent (pGP-I) and secondary (pGP-II). Also, overall proportion of cancer involving prostate volume was estimated coded as V+.

A detailed informed signed consent was obtained by the patients who were preoperatively assessed for simultaneous serum levels of TT, FT and total PSA.

The samples were collected at least one month after prostate biopsies at 8.00 ante meridian and analyzed at our laboratory. TT (normal range: $9-29 \mathrm{nmol} / \mathrm{l}$ ) and PSA (normal range: $2-4 \mathrm{ug} / \mathrm{l}$ ) were measured by immunochemiluminescent test performed by ADVIA Centaur XP Immunoassay System (Siemens Company). FT (normal range: 31-163 pmol/l) was measured by immunoradiometric test (DSL, USA). The population was clustered by sequencing into intervals the range of the PSA/FT index ratio which was obtained by dividing total PSA by FT (PSA/FT index ratio) in each patient. The PSA/FT index ratio ranged between 0.04 to 1.48 .

According to the interval values of the PSA/FT index ratio, patients were clustered in the following 3 patterns: (i) $\mathrm{AB}(0.04 \leq \mathrm{PSA} / \mathrm{FT} \leq 0.18)$ and $\mathrm{CD}(0.18<\mathrm{PSA} / \mathrm{FT} \leq$ 1.48); (ii) $\mathrm{A}(0.04 \leq \mathrm{PSA} / \mathrm{FT} \leq 0.13), \mathrm{B}(0.13<\mathrm{PSA} / \mathrm{FT} \leq$ $0.18), \mathrm{C}(0.18<\mathrm{PSA} / \mathrm{FT} \leq 0.27)$ and $\mathrm{D}(0.27<\mathrm{PSA} / \mathrm{FT}$ $\leq 1.48)$; (iii) $\mathrm{A} 1 \quad(0.04 \leq \mathrm{PSA} / \mathrm{FT} \leq 0.10), \mathrm{A} 2(0.10<$ $\mathrm{PSA} / \mathrm{FT} \leq 0.13), \mathrm{B}(0.13<\mathrm{PSA} / \mathrm{FT} \leq 0.18), \mathrm{C}(0.18<$ $\mathrm{PSA} / \mathrm{FT} \leq 0.27)$, D1 $(0.27<\mathrm{PSA} / \mathrm{FT} \leq 0.43)$ and $\mathrm{D} 2$ $(0.43<\mathrm{PSA} / \mathrm{FT} \leq 1.48)$.

\section{Statistical METHOdS}

It was computed the summary statistics of the patient population of patients who were stratified according to CCR groups in which differences were assessed by the Kruskal-Wallis test (continuous variables) and by the Chi Squared test (categorical variables). The association of FT with PSA was assessed by simple linear regression analysis in either the population and subpopulations of patients who were clustered according to the PSA/FT index ratio. The differences between groups of the population of patients who were clustered according to the PSA/FT index ratio were assessed by the Chi Squared and Kruskal-Wallis statistic tests. The association of the variables, including also the PSA/FT index ratio, with aggressive PCA ( $\mathrm{pGS} \geq 7$ or $\mathrm{pT} 3 \mathrm{~b}$ ) was assessed by logistic regression which also included the analysis of multiple independent clinical models predicting aggressive PCA biology. A two-sided P $<0.05$ was considered to indicate statistical significance.

\section{RESULTS}

The analysis included 220 patients whose summary statistics has already been reported elsewhere $(11,12)$. Table 1 shows the comparing statistics of the 220 operated patients who were stratified according to CCR groups (10). As shown, the CCR groups were significantly different for many of the investigated variables. TT and FT did not show any difference among the CCR groups of patients who however had different values of the PSA/FT index ratio $(\mathrm{P}<0.0001)$.

In the population of patients, TT correlated to FT which significantly associated with PSA (Supplementary Materials Figure 1). Table 2 shows the results of simple linear regression analysis of FT predicting PSA which was always significant in the population, clusters $(A B / C D, A / B / C / D)$ and subclusters (A1/A2 and D1/D2) of patients who were grouped according to the PSA/FT index ratio. Interestingly, the coefficient of determination (R2) progressively increased along the PSA/FT index ratio by which the population was clustered (Table 2) (Supplementary Materials Figures 2-4).

As shown in Table 3, the PSA/FT index not only associated with CCR, high grade ( $\mathrm{pGS}>7$, pGS-I $>3$ ) and high stage (pT3b) PCA, but also contributed in assessing more risk clusters inside each group of CCR (L, I, H), pGS $(6,7,>7)$ and $\mathrm{pT}(2,3 \mathrm{a}, 3 \mathrm{~b})$. In particular, a low PSA/FT index ratio associated with less aggressive PCA (low CCR, grade and stage PCA), while a high PSA/FT index ratio progressively associated with more aggressive and extensive disease (high CCR, high grade and high stage disease). The PSA/FT index ratio directly and significantly associated with P+ and V+ (biology aggressive PCA) (Supplementary Materials Tables 4a, 4b, 4c). Moreover, as expected, the PSA/FT index ratio directly associated with total PSA and inversely with TT. There was no association of the PSA/FT index ratio with age and WGT of the prostate.

The PSA/FT index ratio was a significant and strong independent predictor which directly associated with $\mathrm{pGS} \geq 7$ (Supplementary Materials Table 5). Interestingly, the PSA/FT index ratio was the strongest independent predictive variable 


\begin{tabular}{|c|c|c|c|c|c|c|c|}
\hline \multirow[b]{2}{*}{ Variables } & & \multirow[b]{2}{*}{ Stat } & \multicolumn{3}{|c|}{$\mathrm{CCR}$} & \multirow[b]{2}{*}{$\begin{array}{l}\text { total } \\
220\end{array}$} & \multirow[b]{2}{*}{$P$-value } \\
\hline & & & $\begin{array}{c}\mathrm{L} \\
(\mathrm{n}=96)\end{array}$ & $\begin{array}{c}1 \\
(n=102)\end{array}$ & $\underset{(\mathrm{n}=22)}{\mathrm{H}}$ & & \\
\hline AGE & years & $\begin{array}{l}\text { mean } \\
\text { SD }\end{array}$ & $\begin{array}{c}65.55 \\
6.27\end{array}$ & $\begin{array}{c}65.35 \\
6.43\end{array}$ & $\begin{array}{c}66.50 \\
5.34\end{array}$ & $\begin{array}{c}65.55 \\
6.24\end{array}$ & 0.73 \\
\hline TT & $\mathrm{nmol} / \mathrm{l}$ & $\begin{array}{c}\text { mean } \\
\text { SD }\end{array}$ & $\begin{array}{c}16.40 \\
5.53\end{array}$ & $\begin{array}{c}16.29 \\
6.43\end{array}$ & $\begin{array}{c}16.95 \\
6.49\end{array}$ & $\begin{array}{c}16.41 \\
6.04\end{array}$ & 0.90 \\
\hline FT & $\mathrm{pmol} / /$ & $\begin{array}{l}\text { mean } \\
\text { SD }\end{array}$ & $\begin{array}{c}34.87 \\
9.29\end{array}$ & $\begin{array}{l}33.47 \\
11.08\end{array}$ & $\begin{array}{l}37.03 \\
14.30\end{array}$ & $\begin{array}{l}34.43 \\
10.72\end{array}$ & 0.46 \\
\hline PSA & $\mathrm{ng} / \mathrm{ml}$ & $\begin{array}{l}\text { mean } \\
\text { SD }\end{array}$ & $\begin{array}{l}5.65 \\
2.02\end{array}$ & $\begin{array}{l}7.37 \\
4.04\end{array}$ & $\begin{array}{l}22.32 \\
12.97\end{array}$ & $\begin{array}{l}8.11 \\
6.97\end{array}$ & $<0.00001$ \\
\hline PSA/FT & $(\mathrm{ng} / \mathrm{ml}) / \mathrm{pmol} / \mathrm{l})$ & $\begin{array}{l}\text { mean } \\
\text { SD }\end{array}$ & $\begin{array}{l}0.17 \\
0.06\end{array}$ & $\begin{array}{l}0.24 \\
0.15\end{array}$ & $\begin{array}{l}0.25 \\
0.37\end{array}$ & $\begin{array}{l}0.24 \\
0.20\end{array}$ & $<0.0001$ \\
\hline $\mathrm{P}+$ & proportion & $\begin{array}{c}\text { mean } \\
\text { SD }\end{array}$ & $\begin{array}{l}0.23 \\
0.15\end{array}$ & $\begin{array}{l}0.42 \\
0.21\end{array}$ & $\begin{array}{l}0.47 \\
0.23\end{array}$ & $\begin{array}{l}0.34 \\
0.21\end{array}$ & $<0.0001$ \\
\hline$V+$ & proportion & $\begin{array}{c}\text { mean } \\
\text { SD }\end{array}$ & $\begin{array}{l}0.12 \\
0.09\end{array}$ & $\begin{array}{l}0.21 \\
0.15\end{array}$ & $\begin{array}{l}0.36 \\
0.26\end{array}$ & $\begin{array}{l}0.19 \\
0.16\end{array}$ & $<0.0001$ \\
\hline $\mathrm{pGS} \leq 6$ & $\begin{array}{l}\text { Yes } \\
\text { No }\end{array}$ & $\begin{array}{c}n \\
\% \text { total } \\
n \\
\% \text { total }\end{array}$ & $\begin{array}{c}61 \\
27.7 \\
35 \\
15.9\end{array}$ & $\begin{array}{c}24 \\
10.9 \\
78 \\
35.5\end{array}$ & $\begin{array}{c}3 \\
1.4 \\
19 \\
8.6\end{array}$ & $\begin{array}{c}88 \\
40.0 \\
132 \\
60.0\end{array}$ & $<0.00001$ \\
\hline $\mathrm{pGS}=7$ & $\begin{array}{l}\text { Yes } \\
\text { No }\end{array}$ & $\begin{array}{c}n \\
\% \text { total } \\
n \\
\% \text { total }\end{array}$ & $\begin{array}{c}33 \\
15.0 \\
63 \\
28.6\end{array}$ & $\begin{array}{c}68 \\
30.9 \\
34 \\
15.5\end{array}$ & $\begin{array}{c}8 \\
3.6 \\
14 \\
6.4\end{array}$ & $\begin{array}{c}109 \\
49.5 \\
111 \\
50.5\end{array}$ & $<0.00001$ \\
\hline pGS $>7$ & $\begin{array}{l}\text { Yes } \\
\text { No }\end{array}$ & $\begin{array}{c}n \\
\% \text { total } \\
n \\
\% \text { total }\end{array}$ & $\begin{array}{c}2 \\
0.9 \\
94 \\
42.7\end{array}$ & $\begin{array}{c}10 \\
4.5 \\
92 \\
41.8\end{array}$ & $\begin{array}{c}11 \\
5.0 \\
11 \\
5.0\end{array}$ & $\begin{array}{c}23 \\
10.5 \\
197 \\
89.5\end{array}$ & $<0.00001$ \\
\hline$I C D$ & $\begin{array}{l}\text { Yes } \\
\text { No }\end{array}$ & $\begin{array}{c}n \\
\% \text { total } \\
n \\
\% \text { total }\end{array}$ & $\begin{array}{c}72 \\
32.7 \\
24 \\
10.9\end{array}$ & $\begin{array}{c}50 \\
22.7 \\
52 \\
23.6\end{array}$ & $\begin{array}{c}3 \\
1.4 \\
19 \\
8.6\end{array}$ & $\begin{array}{c}125 \\
56.8 \\
95 \\
43.2\end{array}$ & $<0.00001$ \\
\hline ECE & $\begin{array}{l}\text { Yes } \\
\text { No }\end{array}$ & $\begin{array}{c}n \\
\% \text { total } \\
n \\
\% \text { total }\end{array}$ & $\begin{array}{c}21 \\
9.5 \\
75 \\
34.1\end{array}$ & $\begin{array}{c}44 \\
20.0 \\
58 \\
26.4\end{array}$ & $\begin{array}{c}9 \\
4.1 \\
13 \\
5.9\end{array}$ & $\begin{array}{c}74 \\
33.6 \\
146 \\
66.4\end{array}$ & 0.005 \\
\hline SVI & $\begin{array}{l}\text { Yes } \\
\text { No }\end{array}$ & $\begin{array}{c}n \\
\% \text { total } \\
n \\
\% \text { total }\end{array}$ & $\begin{array}{c}3 \\
1.4 \\
93 \\
42.3\end{array}$ & $\begin{array}{c}8 \\
3.6 \\
94 \\
42.7\end{array}$ & $\begin{array}{c}10 \\
4.5 \\
12 \\
5.5\end{array}$ & $\begin{array}{l}21 \\
9.5 \\
199 \\
90.5\end{array}$ & $<0.00001$ \\
\hline PSM & Yes & $\begin{array}{c}n \\
\% \text { total } \\
n \\
\% \text { total }\end{array}$ & $\begin{array}{c}27 \\
12.3 \\
69 \\
31.4\end{array}$ & $\begin{array}{c}44 \\
20.0 \\
58 \\
26.4\end{array}$ & $\begin{array}{c}17 \\
7.7 \\
5 \\
2.3\end{array}$ & $\begin{array}{c}88 \\
40.0 \\
132 \\
60.0\end{array}$ & $<0.00001$ \\
\hline
\end{tabular}

Table 1.

Statistics of the patient population stratified according to the D'Amico's class risk.

Legend:

CCR, cancer class risk;

L, low class risk;

I, intermediate class risk; $\mathrm{H}$, high class risk.

which directly associated with $\mathrm{pGS} \geq 7$; indeed, for every increase of one-unit in the PSA/FT index ratio, the risk of pGS $\geq 7$ increased 9.11 times (Supplementary Materials Table 6 model b6). TT, PSA, P+, V+ and PSA/FT associated with pT3b PCA in simple models (Supplementary Materials Table 6 section al-a8).

In multivariate models, the PSA/FT index ratio was a significant and independent predictor of pT3b PCA. Interestingly, the PSA/FT index ratio was the strongest independent variable when predicting pT3b disease (Supplementary Materials Table 6 model b7); indeed, the association indicated that for every increase in one unit of the PSA/FT index ratio, the risk of pT3b increased 54.914 times.

\section{Discussion}

In the present study, we have shown that FT significantly associated with PSA in the population of patients. Since the prediction of FT on PSA was linear, we consequently clustered the population of patients according to the PSA/FT index ratio which geometrically represents the variation of the gradient of the regression line associating FT with PSA (Table 2) (Supplementary Materials Figures 1-4). The PSA/FT index ratio independently associated with biologically aggressive prostate cancer (Supplementary Materials Tables 5-6); moreover, the association was strong since the OR was 9.11 when the $\mathrm{PSA} / \mathrm{FT}$ ratio predicted $\mathrm{pGS} \geq 7$ and 54.91 when it pre- 


\begin{tabular}{|c|c|c|c|c|c|c|c|c|c|c|}
\hline Model & $\mathrm{N}$ & Predictors & B & SDE & $t$-test & $P$-value & $95 \% \mathrm{Cl}$ (inf) & $95 \% \mathrm{Cl}$ (sup) & $\mathrm{R}^{2}$ & \multirow{4}{*}{$\begin{array}{l}\text { Simple linear } \\
\text { regression models } \\
\text { in the population } \\
\text { and subpopulation } \\
\text { of patients } \\
\text { according } \\
\text { to the PSA/FT } \\
\text { index ratio. }\end{array}$} \\
\hline \multicolumn{10}{|l|}{ a) Population } & \\
\hline$A B C D$ & 220 & bo & 4,125 & 1,564 & 2,638 & ,009 & 1,043 & 7,207 & 0,03 & \\
\hline b) Subpopula & & $\mathrm{FT}(\mathrm{pmol} / \mathrm{l})$ & ,116 & ,043 & 2,675 & ,008 & 031 & ,201 & & \\
\hline \multirow[t]{2}{*}{$A B$} & 111 & bo & 1,544 &, 566 & 2,727 & ,007 &, 422 & 2,666 & 0,24 & \\
\hline & & $\mathrm{FT}(\mathrm{pmol} / \mathrm{l})$ & ,085 & ,014 & 5,880 & , 000 & , 056 & 114 & & \\
\hline \multirow[t]{2}{*}{$C D$} & 109 & bo &,- 500 & 2,281 &,- 219 & ,827 & $-5,022$ & 4,021 & 0,22 & \\
\hline & & $\mathrm{FT}(\mathrm{pmol} / \mathrm{l})$ & ,388 &, 070 & 5,563 &, 000 &, 250 &, 526 & & \\
\hline \multicolumn{11}{|c|}{ c) Subpopulations } \\
\hline \multirow[t]{2}{*}{ A } & 57 & bo & 158 & ,592 & 268 & ,790 & $-1,028$ & 1,344 & 0,44 & \\
\hline & & $\mathrm{FT}(\mathrm{pmol} / \mathrm{l})$ & 093 &, 014 & 6,588 &, 000 &, 065 &, 121 & & \\
\hline \multirow[t]{2}{*}{ B } & 54 & bo &,- 056 & ,407 &,- 138 & 891 &,- 874 & ,762 & 0,80 & \\
\hline & & $\mathrm{FT}(\mathrm{pmol} / \mathrm{l})$ & , 163 & , 011 & 14,381 & , 000 & 141 & 186 & & \\
\hline \multirow[t]{2}{*}{ c } & 55 & bo &,- 711 & ,309 & $-2,303$ & ,025 & $-1,331$ & -,092 & 0,94 & \\
\hline & & $\mathrm{FT}(\mathrm{pmol} / \mathrm{l})$ &, 256 & 009 & 27,622 &, 000 &, 237 & ,275 & & \\
\hline \multirow[t]{2}{*}{$\mathrm{D}$} & 54 & bo & $-1,883$ & 3,500 &,- 538 &, 593 & $-8,907$ & 5,141 & 0,35 & \\
\hline & & $\mathrm{FT}(\mathrm{pmol} / \mathrm{l})$ & ,582 & 109 & 5,320 & ,000 & ,362 & ,801 & & \\
\hline \multicolumn{11}{|c|}{ c) Sublcusters of $A$} \\
\hline \multirow[t]{2}{*}{ A1 } & 30 & bo & ,741 &, 539 & 1,375 & 180 &,- 363 & 1,845 & 0,41 & \\
\hline & & $\mathrm{FT}(\mathrm{pmol} / \mathrm{l})$ & ,058 & ,013 & 4,441 & ,000 & ,031 & ,085 & & \\
\hline \multirow[t]{2}{*}{ A2 } & 27 & bo &,- 124 &, 326 &,- 381 & ,706 &,- 796 & ,547 & 0,91 & \\
\hline & & $\mathrm{FT}(\mathrm{pmol} / \mathrm{l})$ & ,121 & ,008 & 15,899 & , 000 & 106 & 137 & & \\
\hline \multicolumn{11}{|c|}{ d) Subclusters of D } \\
\hline \multirow{3}{*}{ D1 } & 20 & & & & & & & & & Legend: \\
\hline & 29 & FT (pmpl/l) & $\begin{array}{l}4 / 3 \\
314\end{array}$ & , & , 12630 & , 542 & $-1,097$ & $\begin{array}{l}2,043 \\
365\end{array}$ & 0,86 & B, coefficient; \\
\hline & & & & & & & & & & SDE, standard deviation error; \\
\hline \multirow[t]{2}{*}{$\mathrm{D} 2$} & 25 & bo & 1,944 & 4,356 & ,446 & 660 & $-7,068$ & 10,957 & 0,53 & FT, FT predictor: \\
\hline & & $F \mid(\mathrm{pmol} / \mathrm{I})$ & 年, 666 & , 130 & 5,105 & , ب & , 396 & & & $R^{2}$, coefficient of determination. \\
\hline
\end{tabular}

Table 3.

Statistics of the categorical variables of the patient population $(n=200)$ stratified according to the PSA/FT index ratio. in different clusters.

\begin{tabular}{|c|c|c|c|c|c|c|c|c|c|c|c|}
\hline \multirow[b]{3}{*}{ Clusters } & & & \multicolumn{3}{|c|}{ CCR } & \multicolumn{3}{|c|}{ pGS } & \multicolumn{3}{|c|}{ pT } \\
\hline & \multicolumn{2}{|c|}{ PSA/FT } & $\bar{L}$ & 1 & $\mathrm{H}$ & 6 & 7 & $>7$ & 2 & $3 a$ & $3 b$ \\
\hline & $L$ & $U$ & $n(\%)$ & $n(\%)$ & $n(\%)$ & $n(\%)$ & $\mathrm{n}(\%)$ & $\mathrm{n}(\%)$ & $\mathrm{n}(\%)$ & $n(\%)$ & $\mathrm{n}(\%)$ \\
\hline$A B$ & $\geq 0,04$ & $\leq 0,18$ & $62(64,6)$ & $49(48,0)$ & $0(0,0)$ & $49(55,7)$ & $55(50,5)$ & $7(30,4)$ & $73(58,4)$ & $33(44,6)$ & $5(23,8)$ \\
\hline$C D$ & $>0,18$ & $\leq 1,48$ & $34(35,4)$ & $53(52,0)$ & $22(100,0)$ & $39(44,3)$ & $54(49,5)$ & $16(69,6)$ & $52(41,6)$ & $41(55,4)$ & $16(76,2)$ \\
\hline Total & & & 96 & 102 & 22 & 88 & 109 & 23 & 125 & 74 & 21 \\
\hline$P$-value & & & $<0,0001$ & & & 0,09 & & & 0,006 & & \\
\hline A & $\geq 0,04$ & $\leq 0,13$ & $33(34,4)$ & $24(23,5)$ & $0(0,0)$ & $27(30,7)$ & $25(22,9)$ & $5(21,7)$ & $40(32,0)$ & $15(20,3)$ & $2(9,5)$ \\
\hline B & $>0,13$ & $\leq 0,18$ & $29(30,2)$ & $25(24,5)$ & $0(0,0)$ & $22(25,0)$ & $30(27,5)$ & $2(8,7)$ & $33(26,4)$ & $18(24,3)$ & $3(14,3)$ \\
\hline c & $>0,18$ & $\leq 0,27$ & $26(27,1)$ & $22(21,6)$ & $7(31,8)$ & $25(28,4)$ & $24(22)$ & $6(26,1)$ & $37(29,6)$ & $14(18,9)$ & $4(19,0)$ \\
\hline D & $>0,27$ & $\leq 1,48$ & $8(8,3)$ & $31(30,4)$ & $15(68,2)$ & $14(15,9)$ & $30(27,5)$ & $10(43,5)$ & $15(12,0)$ & $27(36,5)$ & $12(57,1)$ \\
\hline $\begin{array}{l}\text { Total } \\
\end{array}$ & & & 96 & 102 & 22 & 88 & 109 & 23 & 125 & 74 & 21 \\
\hline$P$-value & & & $<0,0001$ & & & 0,07 & & & $<0,0001$ & & \\
\hline $\mathrm{A} 1$ & $\geq 0,04$ & $\leq 0,10$ & $14(14,6)$ & $16(15,7)$ & $0(0,0)$ & $13(14,8)$ & $13(11,9)$ & $4(17,4)$ & $21(16,8)$ & $8(10,8)$ & $1(4,8)$ \\
\hline $\mathrm{A} 2$ & $>0,10$ & $\leq 0,13$ & $19(19,8)$ & $8(7,8)$ & $0(0,0)$ & $14(15,9)$ & $12(11,0)$ & $1(4,3)$ & $19(15,2)$ & $7(9,5)$ & $1(4,8)$ \\
\hline B & $>0,13$ & $\leq 0,18$ & $29(30,2)$ & $25(24,5)$ & $0(0,0)$ & $22(25,0)$ & $30(27,5)$ & $2(8,7)$ & $33(26,4)$ & $18(24,3)$ & $3(14,3)$ \\
\hline C & $>0,18$ & $\leq 0,27$ & $26(27,1)$ & $22(21,6)$ & $7(31,8)$ & $25(28,4)$ & $24(22,0)$ & $6(26,1)$ & $37(29,6)$ & $14(18,9)$ & $4(19,0)$ \\
\hline D1 & $>0,27$ & $\leq 0,43$ & $8(8,3)$ & $19(18,6)$ & $2(9,1)$ & $8(9,1)$ & $19(17,4)$ & $2(8,7)$ & $11(8,8)$ & $14(18,9)$ & $4(19,0)$ \\
\hline D2 & $>0,43$ & $\leq 1,48$ & $0(0,0)$ & $12(11,8)$ & $13(59,1)$ & $6(6,8)$ & $11(10,1)$ & $8(34,8)$ & $4(3,2)$ & $13(17,6)$ & $8(38,1)$ \\
\hline Total & & & 96 & 102 & 22 & 88 & 109 & 23 & 125 & 74 & 21 \\
\hline$P$-value & & & $<0,0001$ & & & 0,01 & & & $<0,0001$ & & \\
\hline
\end{tabular}

Legend: B, coefficient; SDE, standard deviation error; bo, constant; FT, FT predictor; $R^{2}$, coefficient of determination. 
dicted pT3b. The measure of the association with PCA is interesting; indeed, when the PSA/FT index ratio predicted $\mathrm{pGS} \geq 7$, the $\mathrm{OR}$ indicated that for every increase of one-unit in the PSA/FT index ratio, the risk of $\mathrm{pGS} \geq$ 7 increased 9.11 times; moreover, when it independently predicted $\mathrm{pT} 3 \mathrm{~b}$, the OR indicated that for every increase in one unit of the PSA/FT index ratio, the risk of pT3b increased 54.91 times. Because of the strong association with either $\mathrm{pGS} \geq 7$. and $\mathrm{pT} 3 \mathrm{~b}$, the PSA/FT index ratio was effective for grouping preoperatively the patient population in sub clusters according to rising the values of the of the index variable. Interestingly, rising values of the PSA/FT ratio directly associated with PCA biology expressed by tumor grade and stage. The strong association of the PSA/FT index ratio with PCA biology might be related to PCA physiopathology along the hypothalamic-pituitary-testis prostate axis in which FT, since being the biologically active androgen, stimulates either normal and cancerous cells which both produce PSA which not only relates to prostate volume but also to PCA. As a result, the PSA/FT index ratio is a parameter functionality related to PCA biology and this might also explain why, in multivariate logistic models (Supplementary Materials Tables 5-6), the independent prediction of PSA/FT was stronger than PSA in either pGS $\geq 7$ (OR: 9.11 versus 1.05 ) and pT3b (OR: 54.91 versus 1.13). As a theory, the PSA/FT index ratio is a potential prognostic factor because it associates functionally with biology and natural history of PCA (13-16). The present larger study confirms our preliminary investigations which showed that PCA biology relates to either PSA and FT serum levels; moreover, the PSA/FT ratio is as a growing rate parameter which expresses cancer phenotype biology (17-19). Indeed, the production of PSA in most tumors is initially androgen regulated and undergoes a sharp decline following medical or surgical castration (20).

The stratification of PCA patients in CCR groups (L, I, H) is important for prognosis and treatment (3).

However, L -I CCR groups are not homogenous because of the limits related to clinical staging procedures; as a result, high risk PCA is missed. Indeed, low risk PCA may be treated by active surveillance (AS) which offers low cancer specific mortality (21); however, about a third of these cases will progress requiring definitive treatment (21-22). The present investigation showed that the PSA/FT index ratio was a strong independent predictive factor associated with aggressive PCA.

Interestingly, in either L and I CCR, the PSA/FT index ratio identified different clusters (A, B, C, D) and sub clusters (A1, A2, D1, D2). Clusters $C$ and D associated with aggressive PCA which was missed by clinical staging procedures. In H CCR PCA, it was not detected any low risk cluster (A, B) but only high risk ones (C, D).

In our opinion, the PSA/FT index ratio selects PCA patients in prognostic groups because it represents the specific growing rate parameter which is expression of the biology of the tumor (17-19).

The measures of TT and FT serum levels in L-CCR of patients who undergo AS might express prognostic potential. Indeed, it has been shown that, in AS patients, the risk of progression associates with low FT serum levels (23). The present study showed that the PSA/FT index ratio identified clusters (A, B, C, D) in which the mean values of TT and FT were decreasing significantly (Supplementary Materials Table 4); as a result, lower mean levels of androgens were detected in aggressive PCA.

The results of our study might have theoretical drawbacks of PCA molecular biology. Indeed, the PSA/FT index ratio associated with pGS $>7$ (Table 3 ) of which a high rate was detected in subclusters Al (17\%), C (26.1\%) and D2 (34\%); moreover, mean PSA values were detected lower in subclusters Al and C, which showed different mean values of FT (higher in the former and lower in the latter), but increasingly higher in D1-D2 which both had lower mean values of FT (Supplementary Materials Table 4).

As a consequence, we speculate that high grade tumors in A, B clusters have a phenotype which is less aggressive than that in C-D subgroups. However, the hypothesis need to be verified by studies investigating PCA molecular biology.

There are limits in our study which was retrospective, included a small number of cases, did not relate molecular biology to the grade of tumours and lacks of confirmatory studies. Finally, it does not include follow-up which however is still ongoing and will be the subject of further analysis. However, in our opinion, this is the first study that shows, in PCA cases, a functional relationship between PSA and FT which is expressed by the PSA/FT ratio which directly associates with PCA biology.

\section{Conclusions}

Our study shows that the preoperative PSA/FT index ratio is a strong independent factor which directly associates with aggressive PCA features; moreover, it might have prognostic potential for clustering the patient population into risk classes. Confirmatory studies are required.

Tables 4-6 and Figures 1-4 are posted on www.aiua.it

\section{References}

1. Huggins $C$ and Hodges CV. Studies on prostate cancer. I: The effect of castration, of estrogen and of androgen injection on serum phosphatases in metastatic carcinoma of the prostate. Cancer Res. 1941; 1:293-297.

2. Stamey TA, Yang N, Hay AR, et al. Prostate-specific antigen as a serum marker for adenocarcinoma of the prostate. N Engl J Med. 1987; 317:909-916.

3. Armbruster DA. Prostate-specific antigen: biochemistry, analytical methods, and clinical application. Clin Chem. 1993; 39:181-195.

4. Miller LR, Partin AW, Chan DW, et al. Influence of radical prostatectomy on serum hormone levels. J Urol. 1998; 160:449-53.

5. Olsson M, Ekstrom L, Schulze J, et al. Radical prostatectomy: influence on serum and urinary androgen levels. Prostate. 2010; 70:200-205.

6. Harper ME, Pierrepoint CG, Griffiths K. Carcinoma of the prostate: relationship of pretreatment hormone levels to survival. Eur J Cancer Clin Oncol. 1984; 20:477-82.

7. Chen SS, Chen KK, Lin AT, et al. The correlation between pretreatment serum hormone levels and treatment outcome for patients with prostatic cancer and bony metastasis. BJUI. 2002; 89:710-3. 
8. Siegel R, Naishadham D, Jemal A. Cancer Statistic, 2012 CA Cancer J Clin. 2012; 62:10-29.

9. Ferlay J, Autier P, Boniol M, et al. Estimates of the cancer incidence and mortality in Europe in 2006. Ann Oncol. 2007; 18:581-92.

10. D'Amico AV, Whittington R, Malkowicz SB, et al. Biochemical outcome after radical prostatectomy, external beam radiation therapy or interstitial radiation therapy for clinically localized prostate cancer. JAMA. 1998; 280:969-74.

11. Porcaro AB, Petrozziello A, Ghimenton C, et al. Serum total testosterone is a significant preoperative variable independently contributing to separating the prostate cancer population into prostatectomy Gleason score groups. Urol Int. 2013; 91:55-61.

12. Porcaro AB, Petrozziello A, Ghimenton C, et al. Associaations of pretreatment serum total testosterone measurements with pathologydetected Gleason score cancer. Urol Int. 2013 Dec 11. (Epub ahead of print).

13. Pound CR, Partin AW, Eisenberger M, et al. Natural history of progression after PSA elevation following radical prostatectomy. JAMA. 1999; 281:1591-1597.

14. Hull GW, Rabbani F, Abbas FA, et al. Cancer control with radical prostatectomy alone in 1,000 consecutive patients. J Urol. 2002; 167:528-534.

15. Freedland SJ, Humphreys EB, Mangold LA, et al. Risk of prostate cancer-specific mortality following biochemical recurrence after radical prostatectomy. JAMA. 2005; 294:433-439.

16. Cuzik J, Fisher G, Kattan MW, et al. Long-term outcome among men with conservatively treated localized prostate cancer. British Journal of Cancer 2006; 95:1186-1194.

17. Porcaro AB, Migliorini F, Romano M, et al. Investigative clinical study on prostate cancer: on the role of the pretreatment total PSA to free testosterone ratio in selecting different biology groups of prostate cancer patients. Int Urol Nephrol. 2010; 42:673-681.

18. Porcaro AB, Monaco C, Romano $M$, et al. Investigative clinical study on prostate cancer part II: on the role of the pretreatment total PSA to free testosterone ratio as a marker assessing cancer prognostic groups after radical retro pubic prostatectomy. Urol Int. 2010; 85:152-8.

19. Porcaro AB, Petrozziello A, Romano M, et al. Investigative clinical study on prostate cancer part III: exploring total and PSA free testosterone distributions and linear correlations in groups and subgroups of operated prostate cancer patients according to the PSA/FT ratio. Urol Int. 2010; 85:406-9.

20. Sadar MD, Hussain M and Bruchovsky. Prostate cancer: molecular biology of early progression to androgen independence. Endocrine-Related Cancer. 1999; 6:487-502.

21. Dall'Era MA, Albertsen PC, Bangma C, et al. Active surveillance for prostate cancer: a systematic review of the literature. Eur Urol. 2012; 62:976-83.

22. Klotz L, Zhang L, Lam A, et al. Clinical results of long-term follow-up of a large, active surveillance cohort with localized prostate cancer. J Clin Oncol. 2010; 28:126-131.

23. San Francisco IF, Rojas PA, De Wolf W, Morgentaler A. Low free testosterone levels predict disease reclassification in men with prostate cancer undergoing active surveillance. BJUI 2014; 114:229-235.

\section{Correspondence}

Antonio Benito Porcaro, MD (Corresponding Author)

drporcaro@yahoo.com

Azienda Ospedaliera Universitaria Integrata Verona,

Dipartimento ad Attività Integrata di Chirurgia e Oncologia - Pancreas Center,

Divisione Clinicizzata di Urologia, Policlinico GB Rossi

P.le LA Scuro, 10 - 37134 Verona, Italy

Beatrice Caruso, MD

Department of Laboratory Medicine

Ospedale Policlinico, Azienda Ospedaliera Universitaria Integrata, Verona, Italy

Alessandro Terrin, MD

De Luyk Nicolò, MD

Giovanni Cacciamani, MD

Corsi Paolo, MD

Inverardi Davide, $M D$

De Marchi Davide, MD

Roberto Baldassarre, $M D$

Mariangela Cerruto, MD

Stefano Zecchini Antoniolli, MD

Walter Artibani, MD Professor of Urology

Clinica Urologica

Ospedale Policlinico, Azienda Ospedaliera Universitaria Integrata, Verona, Italy

Claudio Ghimenton, MD

Matteo Brunelli, MD

Department of Pathology

Ospedale Policlinico, Azienda Ospedaliera Universitaria Integrata, Verona, Italy

Aldo Petrozziello, MD

Department of Geriatric Medicine

Ospedale Policlinico, Azienda Ospedaliera Universitaria Integrata, Verona, Italy 